Article

\title{
Exploring Intention to Use Shared Electric Bicycles by the Extended Theory of Planned Behavior
}

\author{
Jun Li *, Jiachao Shen and Bicen Jia
}

check for updates

Citation: Li, J.; Shen, J.; Jia, B. Exploring Intention to Use Shared Electric Bicycles by the Extended

Theory of Planned Behavior.

Sustainability 2021, 13, 4137.

https://doi.org/10.3390/su13084137

Received: 18 March 2021

Accepted: 6 April 2021

Published: 8 April 2021

Publisher's Note: MDPI stays neutral with regard to jurisdictional claims in published maps and institutional affiliations.

Copyright: (c) 2021 by the authors. Licensee MDPI, Basel, Switzerland. This article is an open access article distributed under the terms and conditions of the Creative Commons Attribution (CC BY) license (https:// creativecommons.org/licenses/by/ $4.0 /)$.
School of Intelligent Systems Engineering, Sun Yat-sen University, Guangzhou 510000, China; shenjch@mail2.sysu.edu.cn (J.S.); jiabc@mail2.sysu.edu.cn (B.J.)

* Correspondence: stslijun@mail.sysu.edu.cn

\begin{abstract}
In China, shared electric bicycles are developing rapidly, and are widely used by residents. Understanding the factors that affect residents' intention to use shared electric bicycles is important for implementing a policy of developing sustainable transportation. A sample of 751 respondents has been collected in a small-sized Chinese city to analyze residents' intention to use shared electric bicycles, using an extended theory of planned behavior model. The findings reveal that the research model can well explain residents' intention to use shared electric bicycles. Attitude, subjective norm, and perceived behavioral control have direct positive effects on the intention to use shared electric bicycles. Among them, the subjective norm has the greatest impact on the intention to use shared electric bicycles. Environmental concern and policy support have indirect positive effects on the intention to use shared electric bicycles through the partial mediation of attitude and subjective norm. Based on the above analysis, some measures are proposed to guide the development of shared electric bicycles.
\end{abstract}

Keywords: shared electric bicycle; extended theory of planned behavior; environmental concern; policy support

\section{Introduction}

With the process of rapid urbanization in China, the urban population has increased substantially [1]. Apart from dealing with the traditional traffic issues caused by overpopulation and overurbanization, a growing concern about climate change has made the authorities pay more attention to the idea of green travel. There are still many challenges for the sustainable development of cities, among which the most critical factor is sustainable transportation [2,3]. Urban transportation has problems such as traffic pollution, traffic congestion, and traffic accidents, which have a negative impact on the sustainable development of the city.

In this case, residents are increasingly inclined to find more sustainable travel modes, especially in highly congested urban areas [4,5]. Sustainable travel modes include green travel modes such as walking, cycling, and riding electric bicycles. Among them, shared electric bicycle travel has attracted much attention as a new sustainable travel mode [6]. The sharing of shared electric bicycles is a time-sharing lease system [7], which integrates technologies such as the internet, satellite positioning, and smart locks. Operating companies place electric bicycles in crowded areas, such as residential communities and parks, to provide short- and medium-distance travel services to residents, charging them according to their usage time and travel distance. As a comfortable, convenient, and environmentally friendly travel mode, shared electric bicycles can provide a low-carbon solution for shortand medium-distance travel [8].

Currently, shared electric bicycles are deployed in more than 300 cities across the country, and have strong growth potential. Among them, megacities mainly support the development of automobiles and are not friendly to the development of shared electric bicycles. In some cities, the infrastructure of non-motor vehicle transportation is more complete, 
and the accessibility of shared electric bicycles in these cities is relatively high. Residents can rely on shared electric bicycles for their daily travel, which can alleviate the problem of excessive motor vehicles in these cities to a certain extent. According to the China Bicycle Association, the number of electric bicycles in China exceeded 300 million in 2019, with a growth of over $50 \%$ in the past three years. The market transaction size of China's shared electric bicycle segment is expected to grow to 12.410 billion yuan in 2020, an increase of nearly 8 billion yuan compared to 2019 [9]. This means that shared electric bicycles are gradually becoming a significant portion of urban sustainable transportation systems.

At present, China is committed to building a sustainable development society. The government has paid more attention to environmental protection and has issued many policies to support the development of sustainable transportation [10]. The citizens' awareness of environmental protection is increasing. As a sustainable travel mode, the development of shared electric bicycles requires government policies and guidance as well as support from users. In order to implement such policies, analyzing how to increase residents' intention to use shared electric bicycles and exploring the factors that affect users' intention to use shared electric bicycles have great significance for the government and enterprises.

It was indicated that residents' attitude, subjective norm, and perceived behavior control have an great effect on their intentions towards environmentally friendly behavior $[11,12]$. In addition, some scholars suggested environmental concern significantly affect the intention of environmentally friendly behaviors [7,13], and government policy significantly affect the intention of green travel behaviors [14]. However, currently few studies have systematically examined whether environmental concern and policy support will affect residents' intention to use shared electric bicycles based on the TPB (theory of planned behavior). Therefore, inspired by the planned behavior theory, this article explores the factors that affect residents' intention to use shared electric bicycles, especially the effect of environmental concern and policy support on it.

The structure of the paper is as follows: a literature review of shared electric bicycles and the theory of planned behavior are provided in Section 2. The theoretical framework and research hypotheses are described in Section 3. Section 4 displays questionnaire design and data collection. In Section 5, the findings from the analysis are explained. Finally, the conclusions are given in Section 6.

\section{Literature Review}

\subsection{Shared Electric Bicycles}

Electric bicycles are mainly divided into two categories: bicycle-style electric bicycles (BESBs) or scooter-style electric bicycles (SSEBBs), which are larger, heavier, and can travel at faster speeds [15]. In 2004, the National Road Transportation Safety Law classified electric bicycles as non-motorized vehicles; granted them access to non-motorized lanes; and eliminated the demand for driver's licenses, vehicle registration, and helmet wearing for electric bicycles. The enactment of this law, the development of electric bicycles technology, and the ban on fuel motorcycles in some areas have given rise to the widespread use of electric bicycles [16,17]. In 2018, the "Safety Technical Code for Electric Bicycles" revised by the Ministry of Industry and Information Technology restricted electric bicycles to bicycle-style electric bicycles, requiring the maximum design speed to not exceed $25 \mathrm{~km}$ per hour. It also has further requirements on the quality, motor power, and safety performance of the vehicle [18]. This points out the direction for the design of shared electric bicycles. Most of the shared electric bicycles operating in the market meet the requirements of the new national standard, and their safety performance is guaranteed.

Shared electric bicycles are part of public shared bicycle systems. As a supplement to private transportation and public transportation, public shared bicycle systems are an indispensable part of urban transportation. In the past 50 years, the development of the public bicycle system has gone through four generations [19-21]. The latest generation is dockless shared bicycles and shared electric bicycles [22]. This form of borrowing and returning bicycles without piles has greatly improved the convenience, attracted many 
users, and brought the short-term prosperity of shared bicycles. With the development of shared bicycles, its shortcomings are becoming obvious: issues relating to indiscriminate parking, and such parking behaviors possibly impeding the proper functioning of urban traffic [23,24]; shared bicycles only able to be used as a means of public transportation for short-distance travel [25]; etc.

Compared with bicycles, electric bicycles are faster, especially when riding on uphill segments [26]. They can maintain speed with less effort, and provide health benefits [27]. Riding electric bicycles can overcome the effects of some obstacles, such as hills and longer distances, and can increase people's mobility [28]. In addition, shared electric bicycles have stricter control over their placement, making them easier to be managed for the government.

\subsection{The Theory of Planned Behavior}

As the extension of the theory of reasoned action (TRA), the theory of planned behavior (TPB) has good predictive explanatory power for individual behavior [29-32]. Recently, the TPB model has been widely used to explore the intention of environmentally friendly behavior, such as adolescents' intention to commute by car or bicycle [33]. A study of low-carbon commuting showed that attitude, subjective norm, and perceptual behavioral control positively affect commuters' intention to use shared bicycles [34]. It was found that the attitude, subjective norm, and perceived behavior control all have positive effects in influencing the intention to use shared bicycles [30]. The results of these studies suggest that the TPB model is a reliable theory for studying the intention of environmentally friendly behavior [12].

\subsection{Environmental Concern}

Environmental concern represents the degree of an individual's emphasis on environmental issues [35]. Related studies noticed an association between environmental concern and environmentally friendly behavioral intention. Environmental concern can affect environmentally friendly behavioral intention indirectly through a number of variables, rather than directly on environmentally friendly behavioral intention. [36]. For instance, research found that environmental concern indirectly affected customers' intention to adopt hybrid vehicles through attitude and subjective norm [13]; it was found that environmental concern indirectly affect users' intention to use shared bicycles through attitude and subjective norm [7]. The TPB model allows additional variables to be added to improve the predictive explanatory power for behavior intention [29]. Therefore, environmental concern is incorporated into the TPB model to obtain a more comprehensive perspective of intention to use shared electric bicycles.

\subsection{Policy Support}

Policy support refers to the friendliness of the governmental policies toward residents' intention to use green travel modes. Many studies have noticed the relationship between policy support and intention to use green travel modes, and found that policy support is an effective predictor of these intentions. For instance, research found that policy support indirectly affected customers' intentions to use shared electric vehicles through attitude and subjective norm [31]; it was found that policy measures positively influenced intentions of electric vehicle adoption [14]. Therefore, policy support is also incorporated into the TPB model.

\section{Theoretical Framework and Research Hypotheses}

The sharing of shared electric bicycles is a time-sharing lease system [7]. Users complete origin-destination trips by renting electric bicycles. The intention of residents to use shared electric bicycles, a green travel mode, may be influenced by their own consciousness of environmental protection concepts. In addition, as a travel mode serving the public, the government's policy support may be crucial to its future development. 
Therefore, this research incorporated environmental concern and policy support to explore the factors that affect the intention to use shared electric bicycles based on the theory of planned behavior.

According to the TPB model, residents' intention to use shared electric bicycles is directly influenced by individual attitude, subjective norm, and perceived behavioral control. The term attitude denotes the positive or negative evaluation of an individual when using shared electric bicycles. The more positive an individual's evaluation of the shared electric bicycles, the greater the intention to use shared electric bicycles is likely to be [30]. Subjective norm refers to the external support that individuals feel when using shared electric bicycles. The greater the support an individual receives, the greater his intention to use a shared electric bicycles is likely to be [37]; Perceived behavioral control represents the individual's perception of the resources and capabilities available to them when using shared electric bicycles. The more resources and capabilities an individual perceives, the greater the likelihood of their intention to use shared bicycles [38]. Therefore, the research model of intention to use shared electric bicycles is showed in Figure 1, and the following hypotheses are proposed:

Hypothesis 1 (H1). Attitude has a positive effect on residents' intention to use shared electric bicycles.

Hypothesis 2 (H2). Subjective norm has a positive effect on residents' intention to use shared electric bicycles.

Hypothesis 3 (H3). Perceived behavioral control has a positive effect on residents' intention to use shared electric bicycles.

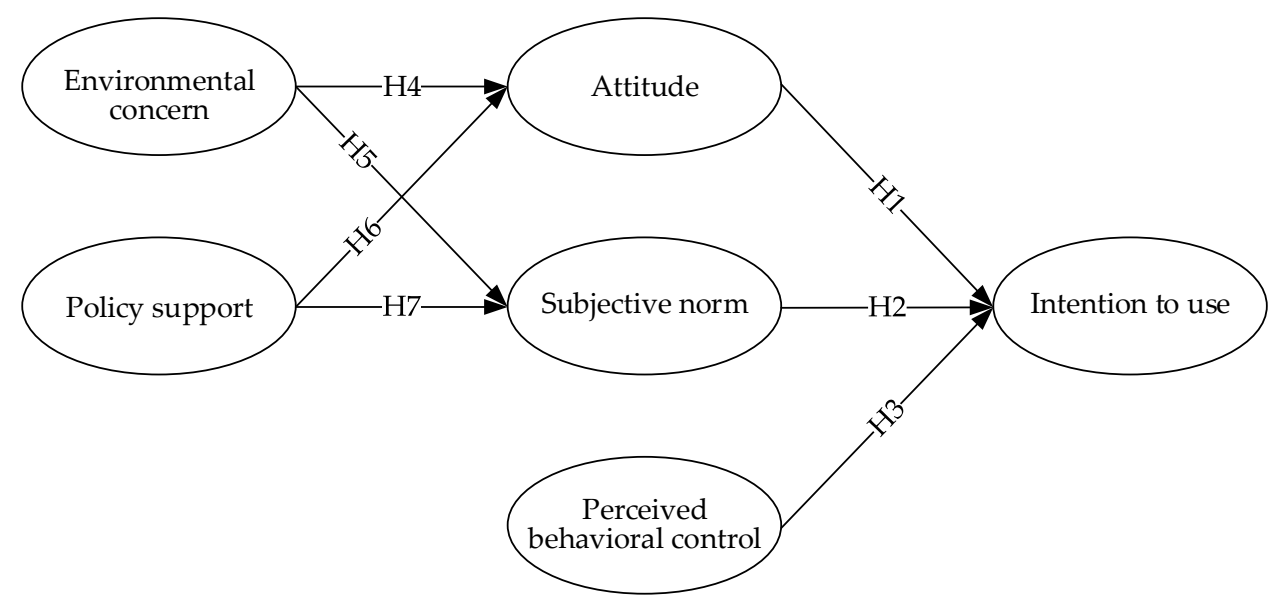

Figure 1. The research model of intention to use shared electric bicycles.

Environmental concern represents the degree of individual's emphasis on environmental issues [35]. The more people consider environmental issues seriously, the more likely they are to engage in a specific environmentally friendly behavior [39]. Riding shared electric bicycles is an environmentally friendly travel mode, and the intention to use it may be affected by individual environmental concern. Environmental concerns indirectly influence specific environmentally friendly behavioral intentions through a number of variables [36]. Therefore, some hypotheses are shown below:

Hypothesis 4 (H4). Environmental concern has a positive effect on attitude.

Hypothesis 5 (H5). Environmental concern has a positive effect on subjective norm. 
Policy support refers to the friendliness of governmental policies toward shared electric bicycles. The more friendly government policies are to green travel, the more residents would intend to use green travel [40]. Riding shared electric bicycles is a green travel behavior, and the intention to use them may be affected by policy support. Policy support indirectly influences green travel behavioral intention through a number of variables [31]. Therefore, the following hypotheses are proposed:

Hypothesis 6 (H6). Policy support has a positive effect on attitude.

Hypothesis 7 (H7). Policy support has a positive effect on subjective norm.

\section{Questionnaire Design and Data Collection}

\subsection{Questionnaire Design}

Questionnaires were used to collect data. The questionnaire consisted of three parts: questionnaire instructions, basic information of the respondent, and the TPB scale. The basic information included gender, age, education, and family monthly income. The TPB scale consisted of six latent variables: environmental concern (EC), policy support (PS), attitude (AT), subjective norm (SN), perceived behavioral control (PBC), and intention to use (IU). The scale items of the TPB variables were adapted from the existing scales of prior research $[7,13,41]$. Furthermore, the scale items of environment concern were adapted from the previous works $[7,11,13]$. The scale items of policy support were adapted from the preceding works $[14,31,42]$. The observed variables of the latent variables were measured using a five-point Likert scale, with one representing strongly disagree and five representing strongly agree, i.e., an increasing level of agreement in that order. Based on consultation with experts and on small-scale tests, the initial questionnaire was revised to form the final questionnaire. The measurement items are shown in Table 1.

Table 1. Measurement items of latent variables.

\begin{tabular}{|c|c|c|}
\hline $\begin{array}{l}\text { Latent } \\
\text { Variable }\end{array}$ & $\begin{array}{l}\text { Title } \\
\text { Item }\end{array}$ & Measurement Items \\
\hline \multirow{4}{*}{ EC } & EC 1 & I think I have responsibility for environmental protection. \\
\hline & EC 2 & $\begin{array}{l}\text { I think that using shared electric bicycles to travel is good for alleviating } \\
\text { environmental pollution. }\end{array}$ \\
\hline & EC 3 & $\begin{array}{l}\text { I think that using shared electric bicycles to travel is good for protecting } \\
\text { the natural environment. }\end{array}$ \\
\hline & EC 4 & $\begin{array}{l}\text { I think that using shared electric bicycles to travel is good for solving } \\
\text { environmental problems. }\end{array}$ \\
\hline \multirow{3}{*}{ PS } & PS 1 & $\begin{array}{l}\text { Governmental policy support for shared electric bicycles will encourage } \\
\text { me to use shared electric bicycles. }\end{array}$ \\
\hline & PS 2 & $\begin{array}{l}\text { Governmental planning and management of shared electric bicycles will } \\
\text { encourage me to use shared electric bicycles. }\end{array}$ \\
\hline & PS 3 & $\begin{array}{l}\text { Governmental restrictions on private car will encourage me to use } \\
\text { shared electric bicycles. }\end{array}$ \\
\hline \multirow{3}{*}{ AT } & AT 1 & Using shared electric bicycles is comfortable. \\
\hline & AT 2 & Using shared electric bicycles is enjoyable. \\
\hline & AT 3 & Using shared electric bicycles is worth encouraging. \\
\hline \multirow{3}{*}{$\mathrm{SN}$} & SN 1 & $\begin{array}{l}\text { People who are important to me support my use of shared } \\
\text { electric bicycles. }\end{array}$ \\
\hline & SN 2 & People whose opinions I value support my use of shared electric bicycles. \\
\hline & SN 3 & $\begin{array}{l}\text { People who are important to me expect me to use shared electric bicycles } \\
\text { to meet part of my travel needs. }\end{array}$ \\
\hline \multirow{4}{*}{ PBC } & PBC 1 & I have the skills to ride shared electric bicycles. \\
\hline & PBC 2 & I have the knowledge to use shared electric bicycles. \\
\hline & PBC 3 & I'm able to pay for the use of shared electric bicycles. \\
\hline & PBC 4 & I have the psychological qualities to deal with riding risks. \\
\hline
\end{tabular}


Table 1. Cont.

\begin{tabular}{cll}
\hline $\begin{array}{c}\text { Latent } \\
\text { Variable }\end{array}$ & $\begin{array}{c}\text { Title } \\
\text { Item }\end{array}$ & \multicolumn{1}{c}{ Measurement Items } \\
\hline & IU 1 & $\begin{array}{l}\text { I will try to use shared electric bicycles. } \\
\text { I will recommend others to use shared electric bicycles. }\end{array}$ \\
IU & IU 2 & $\begin{array}{l}\text { I intend to use shared electric bicycles as a feasible way to travel in } \\
\text { the future. }\end{array}$ \\
& IU 3 & \\
\hline
\end{tabular}

\subsection{Data Collection}

Paper-based questionnaires and web-based questionnaires were delivered randomly in the Meijiang district of Meizhou City. During the preliminary survey, in order to better observe whether respondents correctly understood the questionnaire items, paperbased questionnaires were used to conduct surveys, and adjustments were made to the questionnaire based on this. In formal surveys, web-based questionnaires were used to conduct surveys. Web-based questionnaires have advantages in terms of cost, geographic coverage, and delivery speed compared to the delivery of paper questionnaires by mail or other methods [43]. To encourage the respondent to complete the survey, after the respondent successfully submitted the questionnaire, "lucky money" was given to the respondent as a gift.

Meizhou City is located in the northeast of Guangdong Province, and Meijiang district is the central area of Meizhou City, with a total area of 570.61 square kilometers and a resident population of 421,600 . The city of Meijiang District is small-sized and the daily travel distance of citizens is short. The infrastructure of non-motor vehicle transportation is complete, and the accessibility of shared electric bicycles in these cities is relatively high. Residents can rely on shared electric bicycles for their daily travel, which can alleviate the problem of excessive motor vehicles in these cities to a certain extent. At present, there are many brands and numbers of shared electric bicycles in Meijiang District, and the utilization rate is growing rapidly.

A total of 1096 questionnaires were collected, where 751 were valid. To apply structural equation modeling (SEM), the sample size needed to be at least 200, with 15 times the number of observed variables [44]. The sample size of this study reached the acceptable level required by the SEM model. The statistics of gender, age, education level, and monthly household income of the respondents are shown in Figure 2. As seen, nearly half of the respondents were men, accounting for $50.60 \% .57 .12 \%$ of the respondents were between the ages of 20-40. Respondents had a high level of education, with $53.40 \%$ of them holding a bachelor's degree. $47.01 \%$ of respondents had a monthly household income between RMB 5000 and RMB 12,000 (\$769-\$1844). The population characteristics were similar to those of iiMedia Research's "Special Report on Safety Management of China's Shared Electric Bicycles in 2020", indicating the rationality of the sample selection.
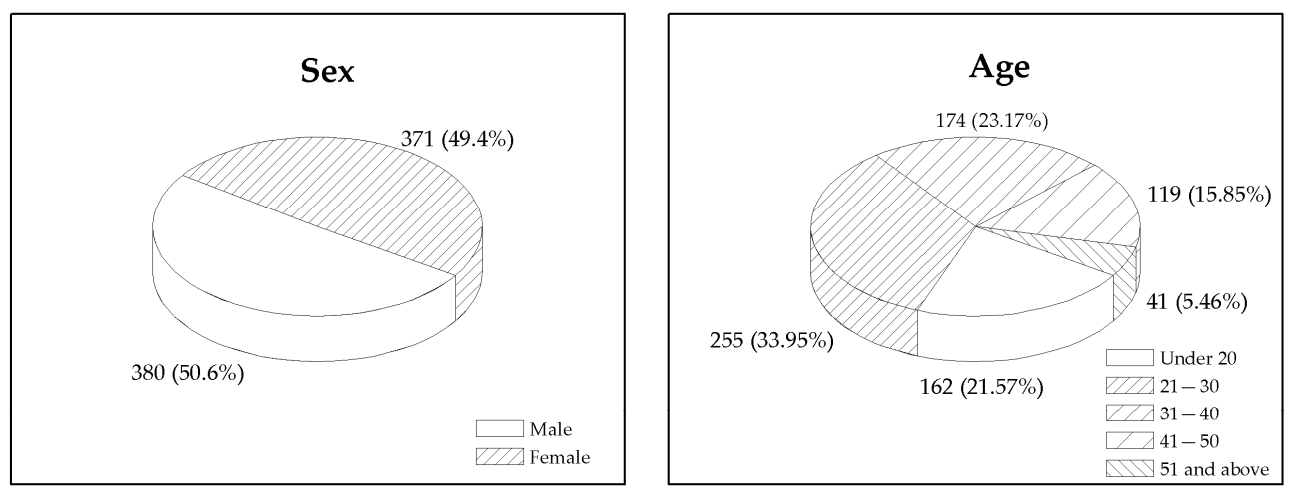

Figure 2. Cont. 

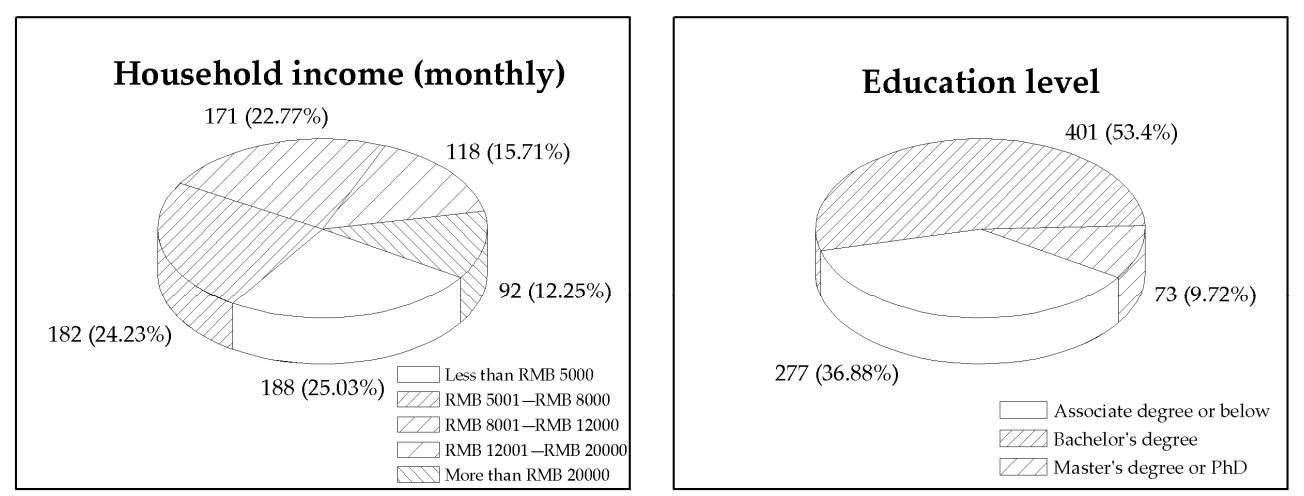

Figure 2. Demographic profile of respondents.

\section{Analysis of Results and Discussion}

\subsection{Reliability and Validity Testing}

In the process of survey research, it is necessary to analyze the reliability and validity of the recovered sample data before data analysis. In the reliability analysis, Cronbach's $\alpha$ coefficient is commonly used to measure the reliability of each factor. When the value of Cronbach's $\alpha$ is greater than 0.7, the measurement model can be considered to have good internal consistency. As illustrated in Table 2, the Cronbach's $\alpha$ values of each latent variable are greater than 0.7 , indicating that the results obtained from the survey using the designed scale are reliable.

Table 2. The confirmatory factor analysis.

\begin{tabular}{|c|c|c|c|c|c|}
\hline Latent Variable & Title Item & $\begin{array}{c}\text { Standardized Factor } \\
\text { Loadings }\end{array}$ & AVE & CR & Cronbach's $\alpha$ \\
\hline \multirow{4}{*}{$\mathrm{EC}$} & EC 1 & 0.660 & \multirow{4}{*}{0.610} & \multirow{4}{*}{0.861} & \multirow{4}{*}{0.853} \\
\hline & EC 2 & 0.855 & & & \\
\hline & EC 3 & 0.861 & & & \\
\hline & EC 4 & 0.729 & & & \\
\hline \multirow{3}{*}{ PS } & PS 1 & 0.848 & \multirow{3}{*}{0.562} & \multirow{3}{*}{0.789} & \multirow{3}{*}{0.772} \\
\hline & PS 2 & 0.798 & & & \\
\hline & PS 3 & 0.574 & & & \\
\hline \multirow{3}{*}{ AT } & AT 1 & 0.779 & \multirow{3}{*}{0.567} & \multirow{3}{*}{0.795} & \multirow{3}{*}{0.782} \\
\hline & AT 2 & 0.827 & & & \\
\hline & AT 3 & 0.640 & & & \\
\hline \multirow{3}{*}{$\mathrm{SN}$} & SN 1 & 0.828 & \multirow{3}{*}{0.646} & \multirow{3}{*}{0.845} & \multirow{3}{*}{0.844} \\
\hline & SN 2 & 0.832 & & & \\
\hline & SN 3 & 0.749 & & & \\
\hline \multirow{4}{*}{ PBC } & PBC 1 & 0.798 & \multirow{4}{*}{0.583} & \multirow{4}{*}{0.848} & \multirow{4}{*}{0.847} \\
\hline & PBC 2 & 0.807 & & & \\
\hline & PBC 3 & 0.684 & & & \\
\hline & PBC 4 & 0.760 & & & \\
\hline \multirow{3}{*}{ IU } & IU 1 & 0.812 & \multirow{3}{*}{0.579} & \multirow{3}{*}{0.805} & \multirow{3}{*}{0.803} \\
\hline & IU 2 & 0.734 & & & \\
\hline & IU 3 & 0.734 & & & \\
\hline
\end{tabular}

AVE is average variance extracted.

In terms of discrimination, it can be concluded from Table 2 that the AVE values of each latent variable are greater than 0.50 , indicating that the average explanatory variance is greater than $50 \%$, and the CR (composite reliability) values are greater than 0.7 . The questionnaire is considered to have good reliability and convergent validity. From Table 3, it can be concluded that the square roots of AVE of each latent variable are higher than 
their corresponding correlations with other latent variables, indicating that the designed questionnaire has a good degree of discrimination.

Table 3. Discriminant validity test.

\begin{tabular}{|c|c|c|c|c|c|c|c|c|}
\hline & Means & Standard Deviation & EC & PS & РBC & SN & AT & UI \\
\hline $\mathrm{EC}$ & 17.22 & 2.669 & 0.781 & & & & & \\
\hline PS & 12.10 & 2.148 & $0.641^{* * *}$ & 0.750 & & & & \\
\hline PBC & 16.70 & 2.877 & $0.615^{* * *}$ & $0.611^{* * *}$ & 0.764 & & & \\
\hline $\mathrm{SN}$ & 11.56 & 2.111 & $0.592 * * *$ & $0.664^{* * *}$ & $0.469^{* * *}$ & 0.804 & & \\
\hline AT & 12.03 & 1.877 & $0.654^{* * *}$ & $0.668^{* * *}$ & $0.494^{* * *}$ & $0.745^{* * *}$ & 0.753 & \\
\hline UI & 12.32 & 2.137 & $0.627^{* * *}$ & $0.657^{* * *}$ & $0.686^{* * *}$ & $0.752^{* * *}$ & $0.726^{* * *}$ & 0.761 \\
\hline
\end{tabular}

The diagonal elements are the square root of AVEs. ${ }^{* * *}$ indicates significance at the $0.1 \%$ level. The non-diagonal elements are the correlation coefficients between the latent variables.

Factor analysis was used to test the overall validity of the questionnaire scales. Before factor analysis, the Kaiser-Meyer-Olkin (KMO) index and Bartlett's sphericity test were used to test whether it was suitable for factor analysis. The KMO value of 0.939 and Bartlett's sphericity test values both showed good validity and are suitable for factor analysis. As shown in Table 2, the standardized factor loadings of the measurement items of each latent variable are all greater than 0.5 , which are statistically significant, indicating that the model is well adapted. In summary, the data collected have a certain degree of reliability and validity.

\subsection{Model Goodness-Of-Fit Testing}

The fitness of the model was tested by seven indicators: $\chi^{2} / \mathrm{df}$ (ratio of chi-square to degrees of freedom), RMSEA (root mean square error of approximation), GFI (goodness of fit index), PGFI (parsimony goodness of fit index), NFI (normed fit index), PNFI (parsimony normed fit index), and CFI (comparative fit index). The model fitting indices are shown in Table 4. Each fit index of the model is within the acceptable range, so the model is acceptable, and the theoretical model fits well with the data.

Table 4. Model fitting indices.

\begin{tabular}{ccc}
\hline Evaluating Indicator & Ideal Value & Model Results \\
\hline$\chi^{2} / \mathrm{df}$ & $<3$ & 2.924 \\
RMSEA & $<0.05$ & 0.051 \\
GFI & $>0.9$ & 0.941 \\
PGFI & $>0.5$ & 0.713 \\
NFI & $>0.9$ & 0.943 \\
PNFI & $>0.5$ & 0.789 \\
CFI & $>0.9$ & 0.962 \\
\hline
\end{tabular}

\subsection{Structural Model and Hypothesis Testing}

A path analysis was conducted with Analysis of Moment Structures (AMOS), and the result is shown in Figure 3. The standardized path coefficient from attitude to intention to use is 0.249 , and it is significant at the $0.1 \%$ level, indicating that model hypothesis $\mathrm{H} 1$ is valid. The standardized path coefficient from subjective norm to intention to use is 0.387 , and it is significant at the $0.1 \%$ level, indicating that model hypothesis $\mathrm{H} 2$ is valid. The standardized path coefficient from perceived behavioral control to intention to use is 0.382 , and it is significant at the $0.1 \%$ level, indicating that model hypothesis $\mathrm{H} 3$ is valid. The standardized path coefficients from environmental concern to attitude and subjective norm are 0.383 and 0.282 , respectively. They were significant at the $0.1 \%$ level, indicating that model hypotheses $\mathrm{H} 4$ and $\mathrm{H} 5$ are valid. The standardized path coefficients from policy support to attitude and subjective norm are 0.423 and 0.483 , respectively. They are both significant at the $0.1 \%$ level, indicating that model hypotheses $\mathrm{H} 6$ and $\mathrm{H} 7$ are valid. In 
addition, based on the value of $\mathrm{R}^{2}$, the variance of residents' intention to use shared electric bicycles is $73.0 \%$, which indicates that the model has sufficient predictive ability.

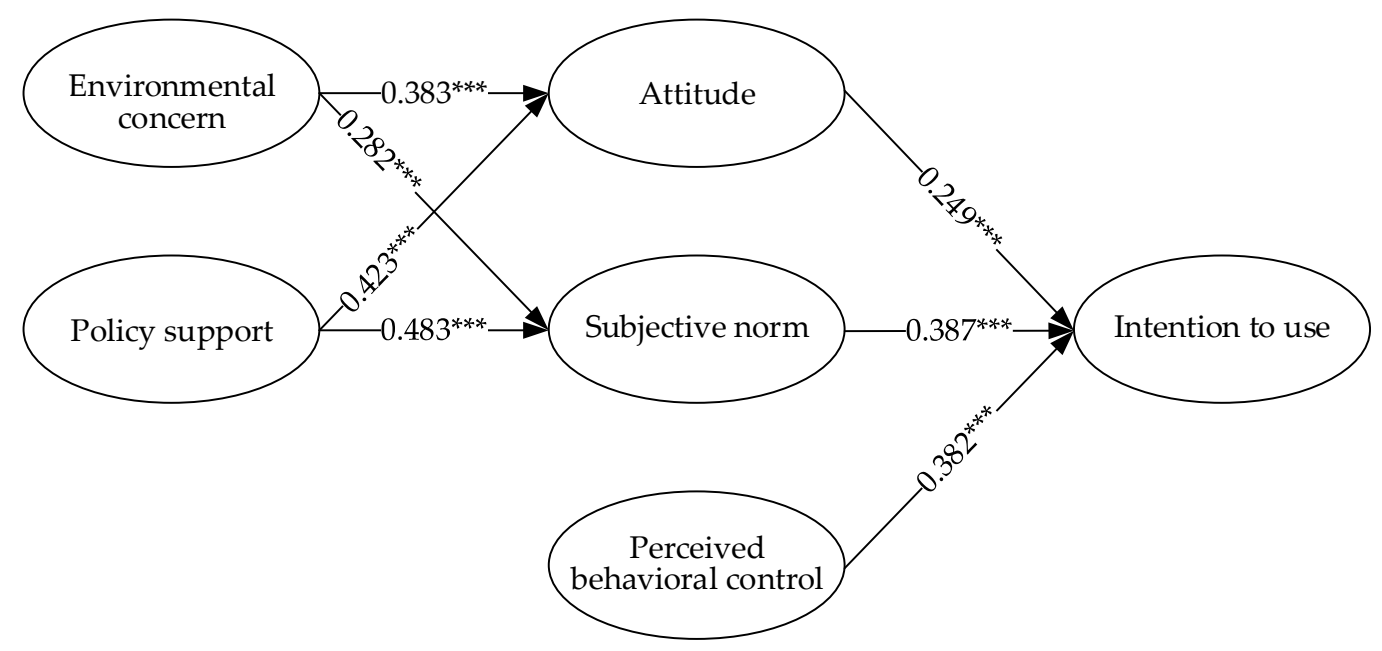

Figure 3. Structural equation model of intention to use shared electric bicycles. ${ }^{* * *}$ indicates significant at the $0.1 \%$ level.

Subjective norm has a direct positive effect on intention to use, and this influence is the greatest, which is similar to the results of prior research [13]. This indicates that users would consider the opinions of their familiars, such as relatives and friends, while using shared electric bicycles. The more agreeable their familiars are, the greater the residents' intention to use shared electric bicycles would be. This is related to the collective consciousness emphasized in daily life, where individual decisions on behavioral intentions tend to be consistent with the collective.

Perceived behavioral control has a direct positive effect on intention to use, indicating that the stronger the user's control over the use of shared electric bicycles is, the greater their intention to use shared electric bicycles would be. Attitude has a direct positive effect on intention to use, indicating that the more positive users' attitudes toward using shared electric bicycles are, the greater their intention to use shared electric bicycles would be. This is consistent with the conclusions of relevant research [30,34]. Attitudes, subjective norms, and perceived behavioral control are all factors that can directly affect residents' intention to use shared travel modes.

\subsection{Test of the Mediating Effect}

Environmental concern and policy support are assumed to have indirect effects on the intention to use shared electric bicycles by taking mediators into consideration. Attitude and subjective norm are mediating variables between environmental concerns, policy support, and intention to use. A mediating effects test was conducted to further explore how environmental concerns and policy support affect residents' intention to use shared electric bicycles [45]. The test steps are as follows:

First, the independent variable is tested to determine whether it significantly affects the dependent variable. Second, the independent variable is tested to see whether it significantly affects the mediating variable. If the results of the aforementioned two steps' test are insignificant, the mediating effect is considered to be nonexistent. Third, a regression analysis is used to see how the independent variable and mediating variable affect the dependent variable. For the mediating effect testing process, a partial mediating effect exists if both the independent variable and mediating variable have a significant effect on the dependent variable, and the coefficient of the independent variable on the dependent variable is smaller than the coefficient of the first step. Otherwise, a full mediating effect is considered to exist.

The mediating effect analysis' results can be shown in Table 5. As shown, the attitude, subjective norm partially mediated the effect of environmental concern and policy sup- 
port on intention to use. Environmental concerns and policy support indirectly affected residents' intention to use shared electric bicycles through attitude and subjective norm.

Table 5. Results of mediating effects test.

\begin{tabular}{cccccccc}
\hline \multirow{2}{*}{ IV } & $\mathbf{M}$ & DV & IV $\rightarrow$ DV & IV $\rightarrow \mathbf{M}$ & \multicolumn{2}{c}{ IV $+\mathbf{M} \rightarrow \mathbf{D V}$} & Results \\
\cline { 6 - 7 } & & & & IV & $\mathbf{M}$ & \\
EC & AT & UI & $0.701^{* * *}$ & $0.624^{* * *}$ & $0.417^{* * *}$ & $0.452^{* * *}$ & Partial mediation \\
EC & SN & UI & $0.701^{* * *}$ & $0.572^{* * *}$ & $0.399^{* * *}$ & $0.530^{* * *}$ & Partial mediation \\
PS & AT & UI & $0.724^{* * *}$ & $0.635^{* * *}$ & $0.454^{* * *}$ & $0.422^{* * *}$ & Partial mediation \\
PS & SN & UI & $0.724^{* * *}$ & $0.643^{* * *}$ & $0.407^{* * *}$ & $0.496^{* * *}$ & Partial mediation \\
\hline *** indicates significant at the $0.1 \%$ level. & & & &
\end{tabular}

Environmental concern positively influences intention to use through the mediation of attitude and subjective norm, and similar conclusions can be drawn in relevant research $[7,13]$. This indicates that the more residents are concerned with environmental issues and agree that using electric bicycle-sharing is good for the environment, the greater their attitude and subjective norm towards shared electric bicycles will be, which leads to greater intention to use shared electric bicycles.

Policy support positively influences intention to use through the mediation of attitude and subjective norm, which is consistent with the conclusions of related research [14,31]. This indicates that government policy support for shared electric bicycles, such as introducing norms to guide the development of shared electric bicycles, can improve residents attitude and subjective norm toward shared electric bicycles, and thus increase the intention to use shared electric bicycles.

\subsection{Discussion}

According to the analysis results of the structural equation model, it can be concluded that residents' intention to use shared electric bicycles has the following characteristics: first, attitude, subjective norm, and perceived behavioral control all have direct positive effects on the intention to use shared electric bicycles. Among them, subjective norm has the greatest effect on the intention to use shared electric bicycles. Second, environmental concern and policy support can positively affect the intention to use shared electric bicycles through mediating effect. Based on the above characteristics, to promote the development of shared electric bicycles, the following measures are proposed for reference:

For users, service quality of shared electric bicycles is crucial. Attitude and perceived behavioral control have significant positive effects on intention to use. Attitude and perceived behavioral control are closely related to the service quality of shared electric bicycles. It is recommended that companies increase the humanized design of electric bicycles and install shock absorption devices to improve the comfort of the riding experience. Repair faulty electric bicycles in a timely manner to reduce potential safety hazards of electric bicycles. Simplify the procedures for using shared electric bicycles and mark parking areas to reduce obstacles for users when using them.

For the company, marketing strategies can be improved to encourage more people to use shared electric bicycles. Subjective norm has a significant positive effect on intention to use. It is recommended that companies not only do a good job of traditional media promotion, but also cooperate with social media, such as WeChat, Weibo, or QQ. Encouraging users to post on social media about the positive feelings and advantages of using shared electric bicycles. This is conducive to creating an atmosphere of using shared electric bicycles, and enhancing the intention to use by strengthening the influence of subjective norm. Environmental concern can positively affect the intention to use shared electric bicycles through mediating effect. Currently, the government is emphasizing the promotion of sustainable urban development. Shared electric bicycle companies can cooperate with the government to organize activities to allow residents to experience the use of shared electric bicycles for free. Attracting customers from the perspective of environmental protection 
can not only promote the popularization of shared electric bicycles, but also contribute to the city's sustainable development strategy.

For the government, to better promote the sustainable development of shared electric bicycles, it is necessary to introduce policies to guide them. Policy support can positively affect the intention to use shared electric bicycles through mediating effect. It is recommended that the government issue operating permits to shared electric bicycle companies that meet the standards in order to further regulate companies' operations. At the same time, reasonable planning should be made for the parking areas and number of shared electric bicycles.

\section{Conclusions}

Two latent variables, environmental concern and policy support, were integrated into the original TPB model, and an extended TPB model was established to investigate the factors influencing the intention to use shared electric bicycles.

It is found that the research model can well explain residents' intention to use shared electric bicycles. Attitude, subjective norm, and perceived behavioral control all have direct positive effects on the intention to use shared electric bicycles. Among them, subjective norm has the greatest effect on the intention to use shared electric bicycles. Environmental concern and policy support both have direct positive effects on attitude and subjective norm. Environmental concern and policy support have indirect positive effects on the intention to use shared electric bicycles through the partial mediation of attitude and subjective norm. To promote the development of shared electric bicycles, some measures are proposed for reference from the perspective of the user, the company, and the government.

There are three contributions. First, the application range of the TPB model was extended to the shared electric bicycles field, especially using the TPB model to analyze residents' intention to use shared electric bicycles. Second, the extended TPB model reveals the underlying mechanisms of how environmental concern and policy support affect residents' intention to use shared electric bicycles, which has a high explanatory power $\left(\mathrm{R}^{2}=73.0 \%\right)$. Third, some measures are proposed to guide the sustainable development of shared electric bicycles.

There are certain limitations. First of all, only two latent variables, environmental concern and policy support, were incorporated into the TPB model. Therefore, future studies could consider the influence of other factors and combine them with the TPB model to explore the intention to use shared electric bicycles. Second, the study focuses on the intention to use shared bicycles rather than actual behavior. Therefore, future research can use the latent variables proposed in this research as influencing factors to further explore residents' actual behavior of using shared electric bicycles. Third, the area studied belongs to third- and fourth-tier cities, and whether the conclusions of the article can be extended to large cities requires further research.

Author Contributions: Conceptualization, J.L.; funding acquisition, J.L.; investigation, J.S. and B.J.; methodology, J.S.; software, B.J.; supervision, J.L.; validation, J.L.; writing一original draft, J.S.; writing-review and editing, J.L. All authors have read and agreed to the published version of the manuscript.

Funding: This work was supported by the Research and Development Project in Key Areas of Guangdong Province (No. 2019B090913001).

Institutional Review Board Statement: Ethical review and approval were waived for this study, due to the human subject involved in this study is about residents' intention to use shared electric bicycles. Respondents are recruited on the basis of voluntary and informed consent, and the rights and privacy of the respondents will be protected to the maximum extent possible, with no potential risk to the respondents.

Informed Consent Statement: Informed consent was obtained from all subjects involved in the study. 
Data Availability Statement: The data presented in this study are available on request from the corresponding author. The data are not publicly available due to privacy protection of respondents.

Conflicts of Interest: The authors declare no conflict of interest.

\section{References}

1. Guan, X.; Wei, H.; Lu, S.; Dai, Q.; Su, H. Assessment on the urbanization strategy in China: Achievements, challenges and reflections. Habitat Int. 2018, 71, 97-109. [CrossRef]

2. Xing, Y.; Liang, H.; Xu, D. Sustainable development evaluation of urban traffic system. Procedia Soc. Behav. Sci. 2013, 96, 496-504. [CrossRef]

3. Buzási, A.; Csete, M. Sustainability indicators in assessing urban transport systems. Period. Polytech. Transp. Eng. 2015, 43, 138-145. [CrossRef]

4. Ma, S.; Zhou, Y.; Yu, Z.; Zhang, Y. College Students' Shared Bicycle Use Behavior Based on the NL Model and Factor Analysis. Sustainability 2019, 11, 4538. [CrossRef]

5. Sałabun, W.; Palczewski, K.; Wattróbski, J. Multicriteria Approach to Sustainable Transport Evaluation under Incomplete Knowledge: Electric Bikes Case Study. Sustainability 2019, 11, 3314. [CrossRef]

6. Ling, Z.; Cherry, C.R.; MacArthur, J.H.; Weinert, J.X. Differences of cycling experiences and perceptions between e-bike and bicycle users in the United States. Sustainability 2017, 9, 1662. [CrossRef]

7. Zhu, M.; Hu, X.; Lin, Z.; Li, J.; Wang, S.; Wang, C. Intention to adopt bicycle-sharing in China: Introducing environmental concern into the theory of planned behavior model. Environ. Sci. Pollut. Res. 2020, 27, 41740-41750. [CrossRef]

8. Langford, B.C.; Cherry, C.; Yoon, T.; Worley, S.; Smith, D. North America's first E-Bikeshare: A year of experience. Transp. Res. Rec. 2013, 2387, 120-128. [CrossRef]

9. Tan, C. 2020 China Shared Two-Wheeler Market Special Report; YiGuan Analysis: Beijing, China, 2020.

10. Zhang, K.-M.; Wen, Z.-G. Review and challenges of policies of environmental protection and sustainable development in China. J. Environ. Manag. 2008, 88, 1249-1261. [CrossRef]

11. Ramayah, T.; Lee, J.W.C.; Lim, S. Sustaining the environment through recycling: An empirical study. J. Environ. Manag. 2012, 102, 141-147. [CrossRef]

12. Kaplan, S.; Manca, F.; Nielsen, T.A.S.; Prato, C.G. Intentions to use bike-sharing for holiday cycling: An application of the Theory of Planned Behavior. Tour. Manag. 2015, 47, 34-46. [CrossRef]

13. Wang, S.; Fan, J.; Zhao, D.; Yang, S.; Fu, Y. Predicting consumers' intention to adopt hybrid electric vehicles: Using an extended version of the theory of planned behavior model. Transportation 2016, 43, 123-143. [CrossRef]

14. Wang, S.; Li, J.; Zhao, D. The impact of policy measures on consumer intention to adopt electric vehicles: Evidence from China. Transp. Res. Part A Policy Pract. 2017, 105, 14-26. [CrossRef]

15. Cherry, C.; Cervero, R. Use characteristics and mode choice behavior of electric bike users in China. Transp. Policy 2007, 14, 247-257. [CrossRef]

16. Weinert, J.; Ma, C.; Cherry, C. The transition to electric bikes in China: History and key reasons for rapid growth. Transportation 2007, 34, 301-318. [CrossRef]

17. Weinert, J.; Ogden, J.; Sperling, D.; Burke, A. The future of electric two-wheelers and electric vehicles in China. Energy Policy 2008, 36, 2544-2555. [CrossRef]

18. Wang, R. Analysis of Government Responsibility from the Perspective of Public Service: Taking the Implementation of Compulsory National Standards for Electric Bicycles as an Example. Theory Constr. 2020, 36, 59-64.

19. Home, S. Assault on Culture: Utopian Currents from Lettrisme to Class War. Electrochem. Soc. 1991, 153, $713-718$.

20. Shaheen, S.A.; Guzman, S.; Zhang, H. Bikesharing in Europe, the Americas, and Asia: Past, present, and future. Transp. Res. Rec. 2010, 2143, 159-167. [CrossRef]

21. DeMaio, P. Bike-sharing: History, impacts, models of provision, and future. J. Public Transp. 2009, 12, 41-56. [CrossRef]

22. Shaheen, S.; Martin, E.; Cohen, A. Public bikesharing and modal shift behavior: A comparative study of early bikesharing systems in North America. Int. J. Transp. 2013, 1, 35-54. [CrossRef]

23. Zhao, D.; Wang, D. The Research of Tripartite Collaborative Governance on Disorderly Parking of Shared Bicycles Based on the Theory of Planned Behavior and Motivation Theories-A Case of Beijing, China. Sustainability 2019, 11, 5431. [CrossRef]

24. Xu, D.; Bian, Y.; Rong, J.; Wang, J.; Yin, B. Study on clustering of free-floating bike-sharing parking time series in beijing subway stations. Sustainability 2019, 11, 5439. [CrossRef]

25. Zhao, R.; Yang, L.; Liang, X.; Guo, Y.; Lu, Y.; Zhang, Y.; Ren, X. Last-Mile Travel Mode Choice: Data-Mining Hybrid with Multiple Attribute Decision Making. Sustainability 2019, 11, 6733. [CrossRef]

26. Langford, B.C.; Cherry, C.R.; Bassett, D.R., Jr.; Fitzhugh, E.C.; Dhakal, N. Comparing physical activity of pedal-assist electric bikes with walking and conventional bicycles. J. Transp. Health 2017, 6, 463-473. [CrossRef]

27. Fishman, E.; Cherry, C. E-bikes in the mainstream: Reviewing a decade of research. Transp. Rev. 2016, 36, 72-91. [CrossRef]

28. Fyhri, A.; Heinen, E.; Fearnley, N.; Sundfør, H.B. A push to cycling—exploring the e-bike's role in overcoming barriers to bicycle use with a survey and an intervention study. Int. J. Sustain. Transp. 2017, 11, 681-695. [CrossRef]

29. Ajzen, I. The theory of planned behavior. Organ. Behav. Hum. Decis. Process. 1991, 50, 179-211. [CrossRef] 
30. Yang, H.; Cao, X.; Li, T.; Tian, R. Analysis of willingness and influence factors of urban residents to use shared bikes: A case study of Xi'an. J. Arid Land REsources Environ. 2019, 033, 78-83.

31. Zhang, Y.; Guo, H.; Wang, W.; Wang, X. Modeling Acceptance of Electric Vehicle Sharing based on Theory of Planned Behavior. Road Traffic Saf. 2015, 15, 25-31. [CrossRef]

32. Chen, C.; Chao, W.H. Habitual or reasoned? Using the theory of planned behavior, technology acceptance model, and habit to examine switching intentions toward public transit. Transp. Res. Part F Traffic Psychol. Behav. 2011, 14, 128-137. [CrossRef]

33. Sigurdardottir, S.B.; Kaplan, S.; Møller, M.; Teasdale, T.W. Understanding adolescents' intentions to commute by car or bicycle as adults. Transp. Res. Part D Transp. Environ. 2013, 24, 1-9. [CrossRef]

34. Cai, S.; Long, X.; Li, L.; Liang, H.; Wang, Q.; Ding, X. Determinants of intention and behavior of low carbon commuting through bicycle-sharing in China. J. Clean. Prod. 2019, 212, 602-609. [CrossRef]

35. Schuitema, G.; Anable, J.; Skippon, S.; Kinnear, N. The role of instrumental, hedonic and symbolic attributes in the intention to adopt electric vehicles. Transp. Res. Part A Policy Pract. 2013, 48, 39-49. [CrossRef]

36. Bamberg, S. How does environmental concern influence specific environmentally related behaviors? A new answer to an old question. J. Environ. Psychol. 2003, 23, 21-32. [CrossRef]

37. Haustein, S.; Hunecke, M. Reduced use of environmentally friendly modes of transportation caused by perceived mobility necessities: An extension of the theory of planned behavior 1. J. Appl. Soc. Psychol. 2007, 37, 1856-1883. [CrossRef]

38. Zhang, Y.; Li, L. Intention of Chinese college students to use carsharing: An application of the theory of planned behavior. Transp. Res. Part F Traffic Psychol. Behav. 2020, 75, 106-119. [CrossRef]

39. Bagozzi, R.P.; Dholakia, U.M.; Basuroy, S. How effortful decisions get enacted: The motivating role of decision processes, desires, and anticipated emotions. J. Behav. Decis. Mak. 2003, 16, 273-295. [CrossRef]

40. Chen, S. Using the sustainable modified TAM and TPB to analyze the effects of perceived green value on loyalty to a public bike system. Transp. Res. Part A Policy Pract. 2016, 88, 58-72. [CrossRef]

41. Ajzen, I. Constructing a TPB Questionnaire: Conceptual and Ethodological Considerations; Psychology Press: New York, NY, USA, 2002.

42. Khoo, H.L.; Ong, G.P. Understanding sustainable transport acceptance behavior: A case study of Klang valley, Malaysia. Int. J. Sustain. Transp. 2015, 9, 227-239. [CrossRef]

43. Dillman, D.; Hoboken, N. Mail and internet surveys: The tailored design method (2nd ed.). J. Contin. Educ. Health Prof. 2007, 30, 206.

44. Golob, T.F. Structural equation modeling for travel behavior research. Transp. Res. Part B Methodol. 2003, 37, 1-25. [CrossRef]

45. Baron, R.M.; Kenny, D.A. The moderator-mediator variable distinction in social psychological research: Conceptual, strategic, and statistical considerations. J. Personal. Soc. Psychol. 1986, 51, 1173-1182. [CrossRef] 